\title{
DNA methylation errors at imprinted loci after assisted conception originate in the parental sperm
}

\author{
Hisato Kobayashi ${ }^{1,2}$, Hitoshi Hiura ${ }^{1,2}$, Rosalind M John ${ }^{3}$, Akiko Sato ${ }^{4}$, Eiko Otsu ${ }^{4}$, \\ Naoko Kobayashi ${ }^{1}$, Rei Suzuki ${ }^{1}$, Fumihiko Suzuki ${ }^{2}$, Chika Hayashi $^{2}$, Takafumi Utsunomiya ${ }^{4}$, \\ Nobuo Yaegashi ${ }^{2}$ and Takahiro Arima*,1
}

\author{
${ }^{1}$ Innovation of New Biomedical Engineering Center, Tohoku University Graduate School of Medicine, Sendai, Japan; \\ ${ }^{2}$ Department of Obstetrics and Gynecology, Tohoku University Graduate School of Medicine, Sendai, Japan; ${ }^{3}$ Cardiff \\ School of Biosciences, Cardiff, UK; ${ }^{4}$ St Luke Clinic, Oita, Japan
}

There is an increased prevalence of imprinting disorders, such as Beckwith-Wiedemann syndrome, associated with human assisted reproductive technologies (ART). Work on animal models suggests that in vitro culture may be the source of these imprinting errors. However, in this study we report that, in some cases, the errors are inherited from the father. We analyzed DNA methylation at seven autosomal imprinted loci and the XIST locus in 78 paired DNA samples. In seven out of seventeen cases where there was abnormal DNA methylation in the ART sample (41\%), the identical alterations were present in the parental sperm. Furthermore, we also identified DNA sequence variations in the gene encoding DNMT3L, which were associated with the abnormal paternal DNA methylation. Both the imprinting errors and the DNA sequence variants were more prevalent in patients with oligospermia. Our data suggest that the increase in the incidence of imprinting disorders in individuals born by ART may be due, in some cases, to the use of sperm with intrinsic imprinting mutations.

European Journal of Human Genetics (2009) 17, 1582-1591; doi:10.1038/ejhg.2009.68; published online 27 May 2009

Keywords: genomic imprinting; assisted reproductive technologies; DNA methylation; oligospermic patients; DNA methyltransferase 3-like protein

\section{Introduction}

Recent studies have identified an increased incidence of the normally rare imprinting disorders, Beckwith-Wiedemann syndrome (BWS; NIM130650) and Angelman syndrome (AS; NIM105830), in babies conceived after assisted conceptions. ${ }^{1-3}$ Epigenetic marks acquired in the germ line drive the allele-specific expression of specific 'imprinted' genes in the embryo. ${ }^{4-6}$ One of the best studied epigenetic marks is DNA methylation which is found associated with only one parental allele within discrete locations

${ }^{*}$ Correspondence: Dr T Arima, Innovation of New Biomedical Engineering Center, Tohoku University Graduate School of Medicine, 2-1 Seiryo-cho, Aoba-ku, Sendai, 980-8575, Japan.

Tel: +8122 717 7844; Fax: +8122717 7063;

E-mail: tarima@mail.tains.tohoku.ac.jp

Received 4 July 2008; revised 17 March 2009; accepted 29 March 2009; published online 27 May 2009 known as differentially methylated regions (DMRs). ${ }^{4}$ The identification of epigenetic changes at imprinted loci in assisted reproductive technology (ART) infants has led to the suggestion that the technique itself may predispose embryos to acquire imprinting errors. ${ }^{1-3}$ Both in vitro fertilization (IVF) and intracytoplasmic sperm injection (ICSI) are associated with the increased risk of imprinting disorders and it is not clear at what point these imprinting errors arise. $^{7,8}$

Major epigenetic events take place during both germ cell development and the preimplantation stages of embryonic development. ${ }^{9}$ In vitro culture may expose the genome to environmental factors that prevent the proper establishment of the imprint. However, the risks cannot easily be evaluated for ART treatment because patients who receive ART treatment may differ both demographically and genetically from the general population. 
In mice, the de novo DNA methyltransferase Dnmt3a and the accessory protein DNA methyltransferase 3-like protein (Dnmt3L) are key regulators of DNA methylation co-operating to de novo methylate DNA in the germ line with Dnmt3L functioning to activate the DNA methyltransferase and recognize the target sequence based on nucleosome modification and CpG spacing. ${ }^{10-17}$ Female mice that lack either Dnmt $3 a$ or Dnmt $3 L$ are fertile but their heterozygous progeny lacks the maternal imprint and the mice die before mid-gestation. Male mice that lack these methylases are infertile and oligospermic. ${ }^{12}$

We, and others, previously demonstrated that methylation errors are present at imprinted loci in the sperm of infertile men, particularly those with oligospermia. ${ }^{18,19}$ In this new study, we examined the methylation profile of seven autosomal imprinted genes (H19, GTL2, PEG1, KCNQ1OT1, ZAC, PEG3 and SNRPN) and the X-linked $X I S T$ gene in DNA obtained from ART conceptuses and matched parental sperm to determine whether these alterations were inherited.

\section{Materials and methods}

\section{Conceptus sample collection}

A total of 78 aborted samples, ranging from 6 to 9 weeks gestation (mean 7 weeks and 3 days) were obtained after treatment by ART (IVF and ICSI) after ethics committee approval and written informed consent. Trophoblastic villi were dissected away from decidual tissues and washed repeatedly with the saline solution to avoid maternal contamination. A total of 38 non-ART aborted conceptus samples, ranging from 6 to 8 weeks gestation (mean 7 weeks and 5 days) were used as controls. Parental sperm and genomic DNA were prepared as described previously. ${ }^{19}$

\section{Bisulfite treatment PCR}

Methylation assays were performed using combined bisulfite PCR restriction analysis (COBRA) and bisulfite sequencing. ${ }^{19}$ Seven autosomal imprinted genes (H19, GTL2, PEG1, KCNQ1OT1, ZAC, PEG3 and SNRPN), the $X I S T$ gene and the repetitive sequences (long interspersed nucleotide elements (LINE1) and Alu) were analyzed as described previously. ${ }^{19,20}$ Each DNA sample was treated with sodium bisulfite using the EZ methylation kit (Zymo Research, Orange, CA, USA) and amplified by PCR. Restriction enzymes were as follows: H19, TaqI; GTL2, TaqI; PEG1, Sau3AI; KCNQ1OT1, RsaI; ZAC, RsaI; PEG3, HinfI; SNRPN, BsiEI; XIST, TaiI; Alu, MboI and LINE1, HinfI. Digested samples were resolved on $10 \%$ polyacrylamide gels and/or 3\% agarose gels. Ethidium bromide-stained bands were quantified with a VersaDoc 5000 and Quantity One software (Bio-Rad, Hercules, CA, USA) and percentage of methylated restriction enzyme sites in each genomic sample was calculated from the ratio between the enzymecleaved PCR product and the total amount of PCR product.
PCR products were purified, cloned into pGEM-T (Promega, Madison, WI, USA) and an average of 20 clones per individual sequenced using M13 reverse primer and an automated ABI Prism 3130xl Genetic Analyzer (Applied Biosystems, Foster city, CA, USA). Sodium modification treatments were carried out in duplicate for each DNA sample and at least three independent amplification experiments were performed for each individual examined.

\section{Karyotyping of the chromosomes}

Chromosomal compliment was determined by FISH using multicolored and chromosome-specific probes. Cases of chromosomal number abnormalities, deletion and duplication were omitted. XY karyotypes were determined by the DNA amplification for X- (DMD gene) and Y- (SRY gene) chromosome-specific sequences as described. ${ }^{21}$

\section{Histological examinations}

Histological examination (hematoxylin and eosin) was performed to confirm the diagnosis of the abortion except in the case of trophoblastic neoplasia.

\section{Mutation analyses}

Mutation analyses of DNMT3A and DNMT3L were performed using the DNA obtained from the male patient's blood. Differences in migration were initially identified by PCR and single-strand conformation polymorphism (SSCP) analyses. ${ }^{22}$ Primers used for the amplification and sequencing of DNMT3A and DNMT3L are shown in Supplementary Table. Sequence alterations were identified by direct cycle sequencing using BigDye fluorescent terminators and the $\mathrm{ABI}$ sequencer (Applied Biosystems).

\footnotetext{
Results

Aberrant paternal imprint methylation in the ART-treated conceptus

We first examined the methylation status of seven imprinted loci and the XIST DMR in DNA samples prepared from 78 XY karyotyped ART conceptuses and 38 non-ART conceptuses using COBRA (Figure $1 \mathrm{a}$ and $\mathrm{b}$ ). In women, the XIST DMR is DNA methylated on one $\mathrm{X}$ chromosome whereas the other chromosome is unmethylated. In men, who have only one $\mathrm{X}$ chromosome, the single locus is normally methylated. Abnormal methylation was taken as being over the range of $\pm 2 \mathrm{SD}$ (standard deviations) of the mean of the methylation in the normal fertilization products. Among the 78 ART-treated cases, we found 8 cases of aberrant paternal methylation (H19, 6 cases; GTL2, 2 cases; Table 1 ). We confirmed the results of the COBRA assay by sequencing (Figure 2). We examined global DNA methylation of the non-imprinted repetitive elements Alu and LINE1. There were no detectable differences between ART and normal samples (Table 1; Figure 1c). Loss of DNA methylation was specific to the imprinted loci.
} 

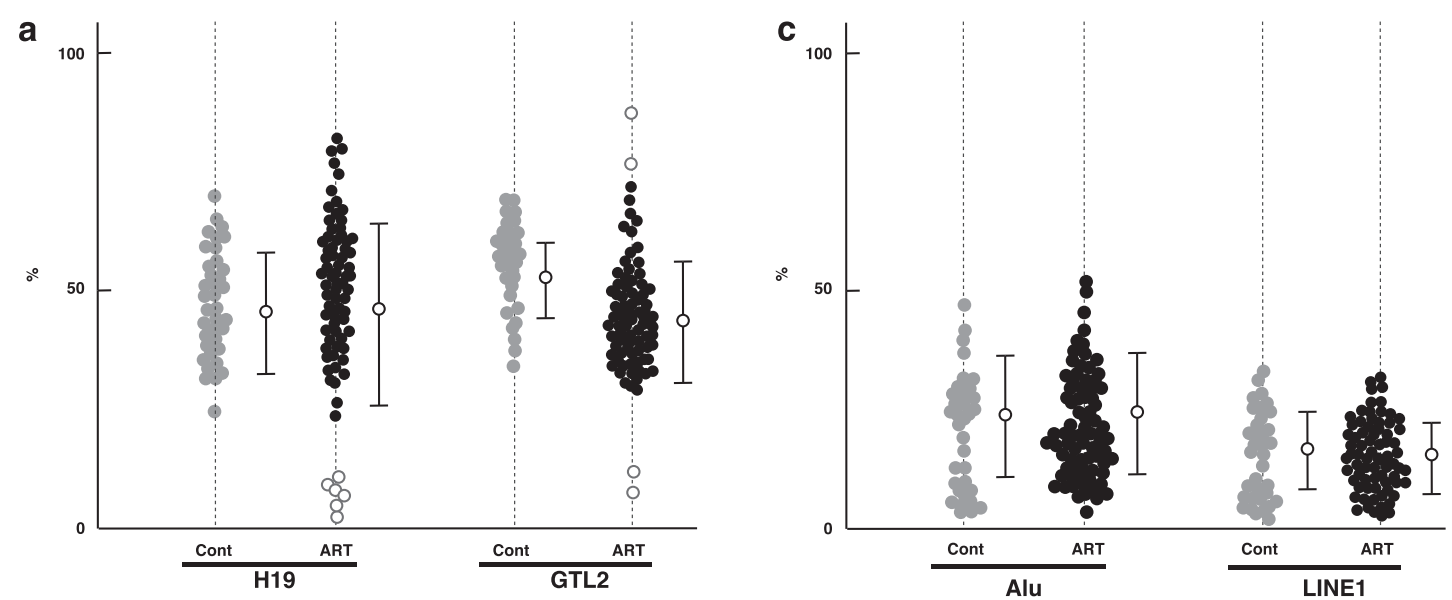

b
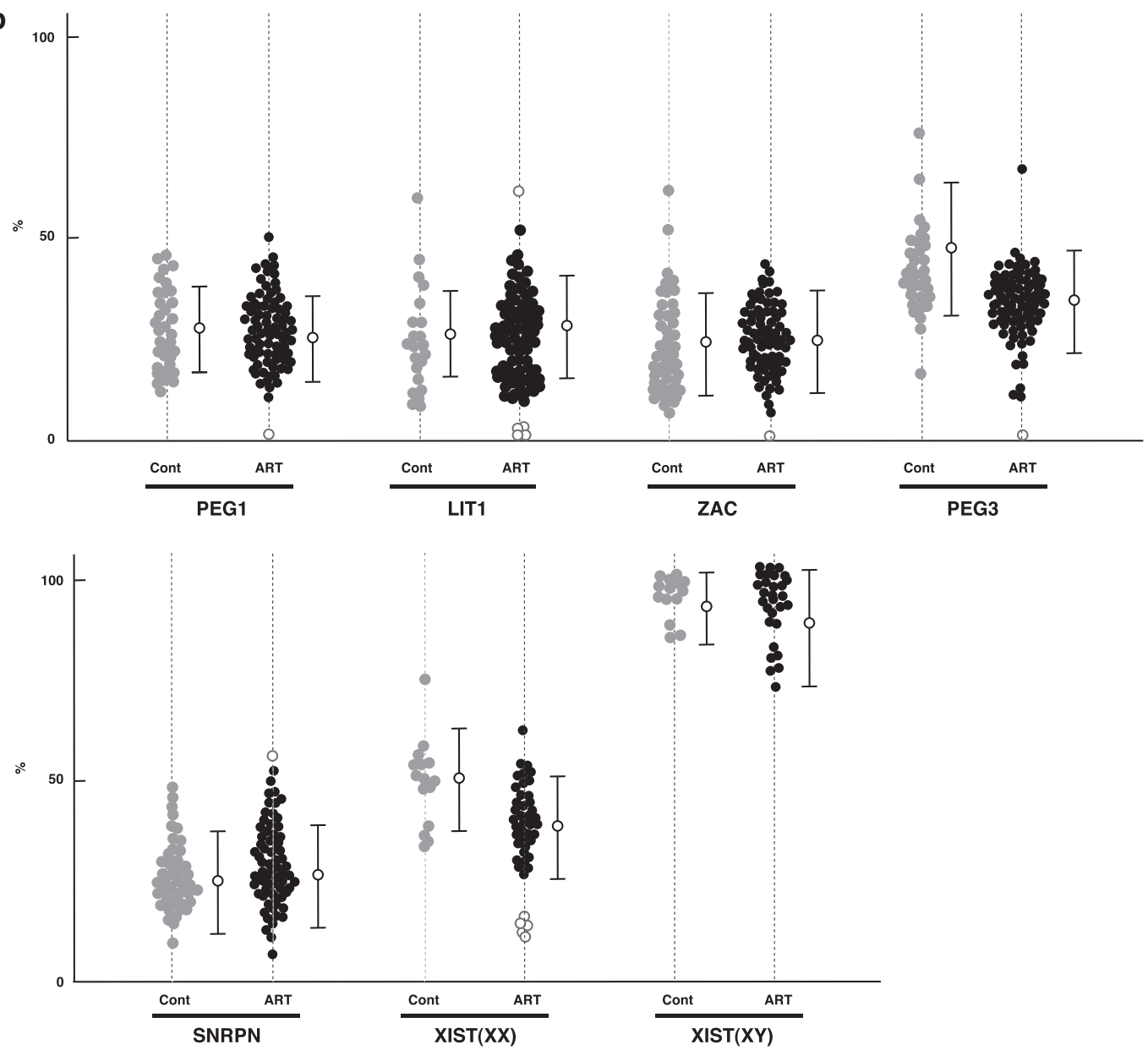

Figure 1 Methylation profile of natural and ART conceptus samples at imprinted and non-imprinted loci. Aberrant methylation over the range of $\pm 2 \mathrm{SD}$ (standard deviations) of the mean of the normal fertilization methylation profile is indicated by red circles. White circles and bar indicate the mean and SD. Paternally methylated loci, H19 and CTL2 (a); maternally methylated loci, PEG1, KCNQ1OT1(LIT1), ZAC, PEG3, SNRPN, XIST of XX karyotype (non-ART conceptus samples, $n=19$; ART, $n=46$ ) and XIST of XY karyotype (non-ART conceptus samples, $n=19 ;$ ART, $n=32$ ) (b), nonimprinted repetitive elements, Alu and LINE1 (c). 
Table 1 Abnormal methylation profiles detected by bisulfite PCR sequence in sperm and ART conceptus DNA

\begin{tabular}{|c|c|c|c|c|c|c|c|c|c|c|c|c|}
\hline \multirow[t]{2}{*}{$\begin{array}{l}\text { Case } \\
\text { (age) }\end{array}$} & \multirow[t]{2}{*}{$\begin{array}{l}\text { ART } \\
\text { treatment }\end{array}$} & \multicolumn{2}{|c|}{$\begin{array}{c}\text { Paternally } \\
\text { methylated DMR }\end{array}$} & \multicolumn{7}{|c|}{$\begin{array}{c}\text { Maternally methylated } \\
\text { DMR }\end{array}$} & \multicolumn{2}{|c|}{$\begin{array}{l}\text { Repetitive } \\
\text { sequences }\end{array}$} \\
\hline & & H19 & GTL2 & PEG 1 & LIT1 & $Z A C$ & PEG3 & SNRPN & $X I S T(X X)$ & $X I S T(X Y)$ & Alu & LINE1 \\
\hline $13(28)$ & IVF (Cryo) & $\begin{array}{c}39.4 \\
(83.1)\end{array}$ & $\begin{array}{c}34.6 \\
(98.6)\end{array}$ & $\begin{array}{l}16.7 \\
(0.0)\end{array}$ & $\begin{array}{l}29.3 \\
(0.0)\end{array}$ & $\begin{array}{l}24.3 \\
(0.0)\end{array}$ & $\begin{array}{l}34.7 \\
(0.0)\end{array}$ & $\begin{array}{l}34.7 \\
(0.0)\end{array}$ & 19.6 & & 45.1 & $\begin{array}{c}29.0 \\
(23.7)\end{array}$ \\
\hline $23(33)^{a}$ & ICSI & $\begin{array}{l}4.0 \\
(9.8)\end{array}$ & $\begin{array}{l}55.8 \\
(99.2)\end{array}$ & $\begin{array}{c}1.1 \\
(0.0)\end{array}$ & $\begin{array}{l}28.1 \\
(0.0)\end{array}$ & $\begin{array}{l}32.4 \\
(2.0)\end{array}$ & $\begin{array}{l}30.6 \\
(0.0)\end{array}$ & $\begin{array}{l}30.6 \\
(0.0)\end{array}$ & & 82.8 & $\begin{array}{c}24.1 \\
(22.8)\end{array}$ & $\begin{array}{l}14.5 \\
(24.4)\end{array}$ \\
\hline $28(39)^{a, b}$ & ICSI & $\begin{array}{c}6.5 \\
(16.7)\end{array}$ & $\begin{array}{l}18.3 \\
(13.5)\end{array}$ & $\begin{array}{c}19.4 \\
(23.0)\end{array}$ & $\begin{array}{l}22.6 \\
(0.0)\end{array}$ & $\begin{array}{l}25.4 \\
(0.0)\end{array}$ & $\begin{array}{l}36.8 \\
(0.0)\end{array}$ & $\begin{array}{l}24.5 \\
(0.0)\end{array}$ & 43.6 & & $\begin{array}{c}26.2 \\
(23.1)\end{array}$ & $\begin{array}{l}11.2 \\
(18.9)\end{array}$ \\
\hline $44(36)^{c}$ & ICSI (Cryo) & $\begin{array}{l}12.8 \\
(9.8)\end{array}$ & $\begin{array}{l}48.9 \\
(99.8)\end{array}$ & $\begin{array}{l}31.4 \\
(0.0)\end{array}$ & $\begin{array}{l}35.4 \\
(0.0)\end{array}$ & $\begin{array}{l}33.6 \\
(0.0)\end{array}$ & $\begin{array}{l}37.8 \\
(0.0)\end{array}$ & $\begin{array}{l}27.8 \\
(0.0)\end{array}$ & & 82.4 & $\begin{array}{c}28.5 \\
(18.9)\end{array}$ & $\begin{array}{l}22.6 \\
(19.2)\end{array}$ \\
\hline $50(43)^{b, c}$ & ICSI & $\begin{array}{l}19.7 \\
(33.3)\end{array}$ & $\begin{array}{c}37.2 \\
(93.1)\end{array}$ & $\begin{array}{l}26.0 \\
(0.0)\end{array}$ & $\begin{array}{l}28.7 \\
(12.0)\end{array}$ & $\begin{array}{l}29.7 \\
(0.0)\end{array}$ & $\begin{array}{l}38.4 \\
(0.0)\end{array}$ & $\begin{array}{l}28.4 \\
(0.0)\end{array}$ & & 78.9 & $\begin{array}{l}12.9 \\
(20.1)\end{array}$ & $\begin{array}{r}21.0 \\
(25.4)\end{array}$ \\
\hline $52(41)^{c}$ & ICSI & $\begin{array}{l}23.5 \\
(17.6)\end{array}$ & $\begin{array}{l}37.3 \\
(96.6)\end{array}$ & $\begin{array}{l}23.0 \\
(1.2)\end{array}$ & $\begin{array}{l}25.1 \\
(0.0)\end{array}$ & $\begin{array}{l}41.3 \\
(0.0)\end{array}$ & $\begin{array}{l}46.2 \\
(0.0)\end{array}$ & $\begin{array}{l}41.3 \\
(0.0)\end{array}$ & & 82.0 & $\begin{array}{l}14.7 \\
(30.3)\end{array}$ & $\begin{array}{l}12.0 \\
(22.4)\end{array}$ \\
\hline $53(34)^{c}$ & ICSI & $\begin{array}{c}57.6 \\
(76.6)\end{array}$ & $\begin{array}{c}33.5 \\
(95.8)\end{array}$ & $\begin{array}{c}29.8 \\
0.0\end{array}$ & $\begin{array}{c}24.9 \\
0.0\end{array}$ & $\begin{array}{l}1.0 \\
0.0\end{array}$ & $\begin{array}{c}42.6 \\
0.0\end{array}$ & $\begin{array}{l}32.6 \\
(5.6)\end{array}$ & 51.3 & & $\begin{array}{c}19.5 \\
(10.4)\end{array}$ & $\begin{array}{r}21.8 \\
(24.4)\end{array}$ \\
\hline $57(42)^{a}$ & ICSI & $\begin{array}{l}41.4 \\
(95.5)\end{array}$ & $\begin{array}{l}16.9 \\
(21.6)\end{array}$ & $\begin{array}{l}31.8 \\
0.0\end{array}$ & $\begin{array}{l}28.1 \\
(3.8)\end{array}$ & $\begin{array}{c}34.9 \\
0.0\end{array}$ & $\begin{array}{l}1.1 \\
0.0\end{array}$ & $\begin{array}{c}25.4 \\
0.0\end{array}$ & 39.4 & & $\begin{array}{c}17.2 \\
(19.2)\end{array}$ & $\begin{array}{r}18.8 \\
(25.4)\end{array}$ \\
\hline 61(33) & IVF & $\begin{array}{c}30.5 \\
(47.6)\end{array}$ & $\begin{array}{c}41.4 \\
(99.0)\end{array}$ & $\begin{array}{c}22.8 \\
0.0\end{array}$ & $\begin{array}{c}20.9 \\
0.0\end{array}$ & $\begin{array}{c}24.0 \\
0.0\end{array}$ & $\begin{array}{c}34.5 \\
0.0\end{array}$ & $\begin{array}{c}34.5 \\
0.0\end{array}$ & 18.3 & & $\begin{array}{c}28.4 \\
(23.1)\end{array}$ & $\begin{array}{c}11.1 \\
(25.1)\end{array}$ \\
\hline $67(36)^{c}$ & IVF & $\begin{array}{c}10.3 \\
(11.8)\end{array}$ & $\begin{array}{c}37.7 \\
(93.5)\end{array}$ & $\begin{array}{c}31.2 \\
0.0\end{array}$ & $\begin{array}{c}26.7 \\
0.0\end{array}$ & $\begin{array}{c}31.1 \\
0.0\end{array}$ & $\begin{array}{c}41.5 \\
0.0\end{array}$ & $\begin{array}{c}28.4 \\
0.0\end{array}$ & & 84.8 & $\begin{array}{c}19.3 \\
(30.3)\end{array}$ & $\begin{array}{r}16.6 \\
(21.4)\end{array}$ \\
\hline $70(36)^{c}$ & IVF & $\begin{array}{c}27.6 \\
(98.6)\end{array}$ & $\begin{array}{c}37.2 \\
(81.6)\end{array}$ & $\begin{array}{c}28.7 \\
0.0\end{array}$ & $\begin{array}{l}3.0 \\
0.0\end{array}$ & $\begin{array}{c}21.8 \\
0.0\end{array}$ & $\begin{array}{c}35.2 \\
0.0\end{array}$ & $\begin{array}{c}51.5 \\
0.0\end{array}$ & 51.3 & & $\begin{array}{c}13.4 \\
(30.6)\end{array}$ & $\begin{array}{c}11.7 \\
(29.2)\end{array}$ \\
\hline $30(32)^{d}$ & Spontaneous & 68.9 & 48.9 & 25.3 & 6.5 & 29.5 & 33.9 & 26.9 & 45.9 & & 19.5 & 22.8 \\
\hline $46(34)^{d}$ & Spontaneous & 44.1 & 34.4 & 26.1 & 1.9 & 28.1 & 41.3 & 41.3 & & 83.8 & 14.7 & 21.8 \\
\hline $62(30)^{d}$ & AlH & 56.7 & 50.4 & 27.6 & 2.3 & 24.1 & 43.2 & 23.4 & & 81.7 & 19.3 & 25.1 \\
\hline $32(27)^{d}$ & Spontaneous & 45.7 & 38.7 & 25.4 & 20.9 & 24.0 & 34.5 & 25.5 & 17.7 & & 20.6 & 21.2 \\
\hline $40(33)^{a, d}$ & AlH & 68.2 & 34.7 & 25.1 & 26.6 & 22.8 & 41.6 & 21.9 & 19.0 & & 26.2 & 21.2 \\
\hline $63(34)^{c, d}$ & AlH & 56.4 & 36.5 & 28.8 & 24.9 & 20.3 & 44.6 & 34.6 & 20.6 & & 19.5 & 22.3 \\
\hline
\end{tabular}

Abbreviations: AlH, artificial insemination by husband; ART, assisted reproductive technology; DMR, differentially methylated region; ICSI, intracytoplasmic sperm injection; IVF, in vitro fertilization.

Each value is the percentage methylation determined by bisulfite PCR sequencing analyses. Bold text highlights the ART-treated conceptuses where mean values are abnormal. The percentage methylation in the parental sperm DNA is shown in parentheses below the value for the conceptus.

${ }^{a}$ Moderate oligospermia (sperm count $\geqslant 5$ to $20 \times 10^{6}$ per $\mathrm{ml}$ ).

${ }^{b}$ In case 28, the nucleotide at position 518 (AAF05812) in exon 2 of DNMT3L was changed from a $\mathrm{G}$ to an A on both alleles of the gene. This is predicted to result in a substitution of Glu to Lys. In case 50, nucleotide 787 of exon 5 of DNMT3L was changed from a C to a T (Table 2).

'Severe oligospermia (sperm count $<5 \times 10^{6}$ per $\mathrm{ml}$ ).

dNot tested in the sperm DNA.

\section{Aberrant maternal imprint methylation in the ART- treated conceptus}

We found 12 cases of aberrant maternal methylation in the ART samples (PEG1, 1 case; KCNQ1OT1, 4 cases; ZAC, 1 case; PEG3, 1 case; XIST, 5 cases; Table 1). The methylation errors were predominantly found at the H19 and KCNQ1OT1 DMRs, which commonly show alterations in DNA methylation in BWS patients. Five cases with an XX female karyotype were found with a methylation defect at the XIST locus but not at the autosomal DMRs. No samples showed complete imprint erasure.

In total, we identified 17 fetal samples with imprint methylation errors. Among them, a completely unmethylated pattern at a single locus was found in 14 cases and a mosaic pattern of aberrant methylation was identified at more than one loci in 3 cases.

Seven cases $(21.8 \%)$ were the products of fertilization by ICSI, four cases $(26.6 \%)$ were the products of IVF, two cases $(11.8 \%)$ were involved a cryopreserved embryo and three cases $(13.0 \%)$ were involved artificial insemination with husband's sperm (AIH). We also identified errors in three samples from our control group. We identified methylation errors in both the ICSI/IVF $(n=39)$ and non-ICSI/IVF $(n=39)$ groups indicating that ICSI was not responsible for these changes. There was no significant difference in the maternal ages between the ICSI/IVF and non-ICSI/IVF groups; $34.3 \pm 4.3$ and $35.0 \pm 3.7$ years old, respectively.

Relationship between aberrant methylation in sperm and conceptus after ART

We compared the quality of the parental sperm sample in the 17 cases where we identified imprinting errors. Seven samples were severely oligospermic (50.0\%), four showed moderate oligospermia (25.0\%) and six appeared normal $(8.6 \%)$. There was an increased frequency in visible sperm abnormalities in the father associated with imprint errors in the conceptuses in line with our previous findings. ${ }^{19}$ 


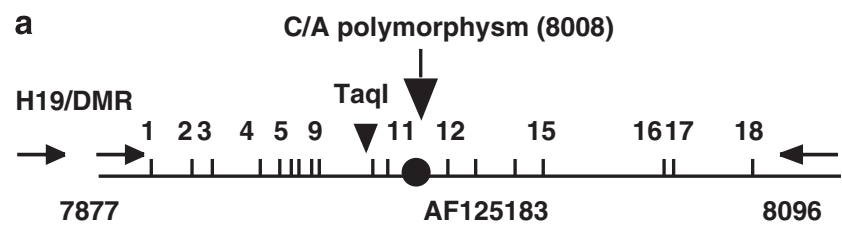

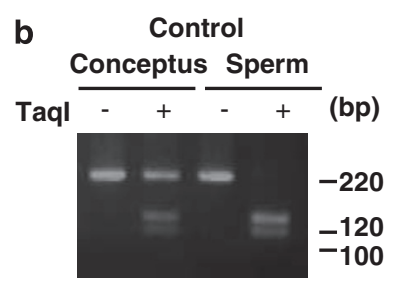
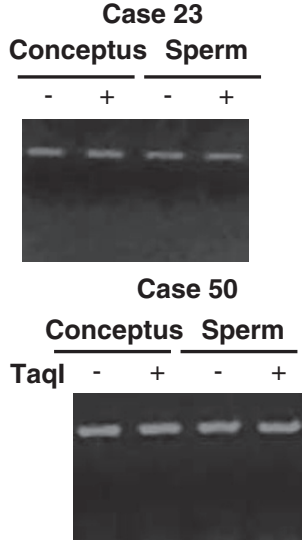

C Control

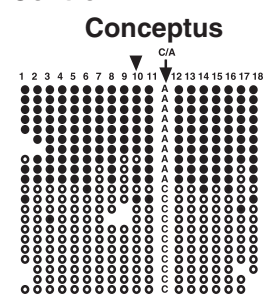

Case 23

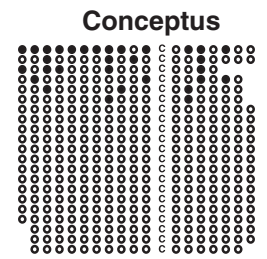

Case 44

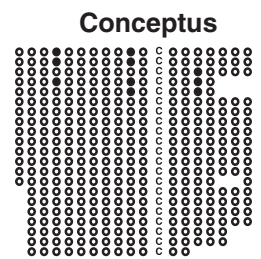

Case 52

Conceptus

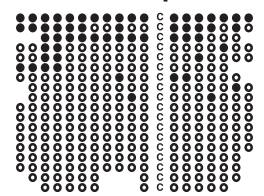

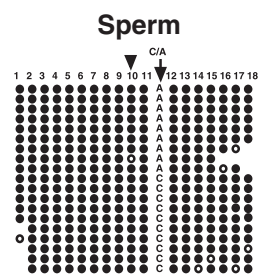
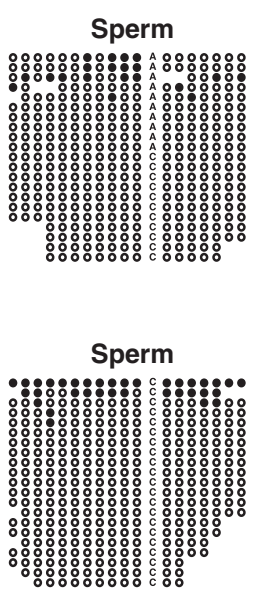

Sperm

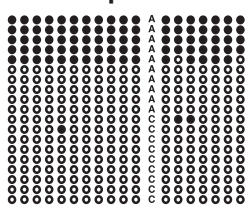

Case 28

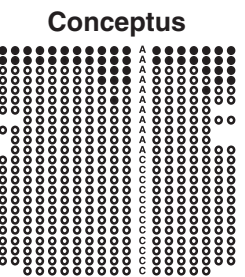

Case 50

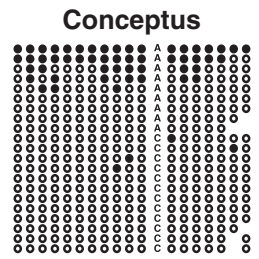

Case 67

Conceptus

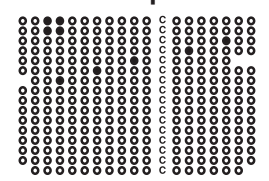

Case 44

Conceptus Sperm

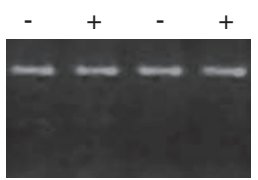

Case 67

Conceptus Sperm

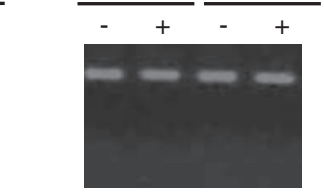

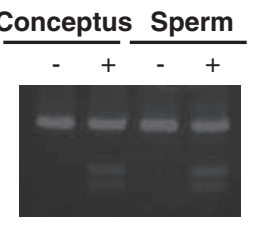

$\frac{\text { Conceptus }}{-+} \frac{\text { Sperm }}{-\quad+}$

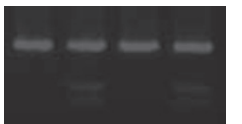

Case 52

\section{m}
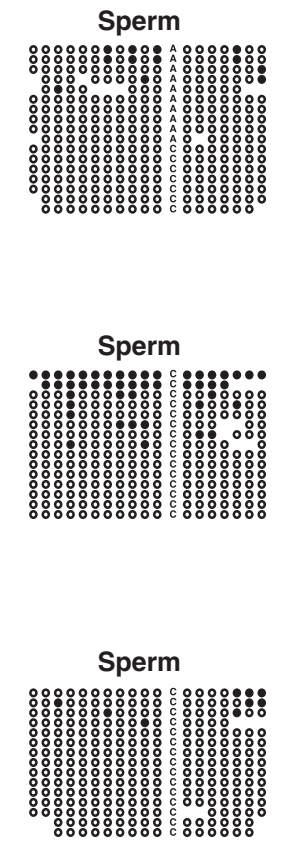

Figure 2 Continued. 


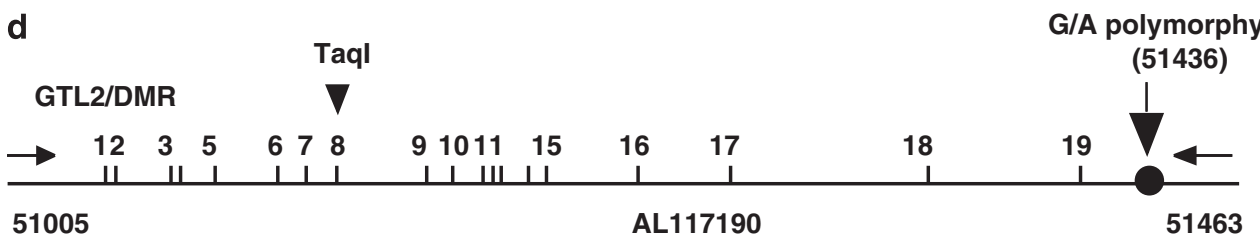

e

Control

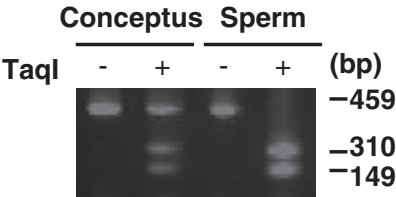

Case 28

Conceptus Sperm

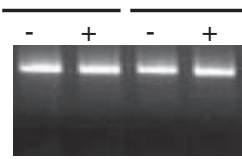

Case 57

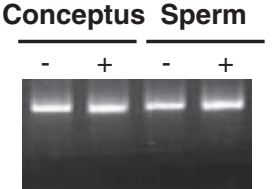

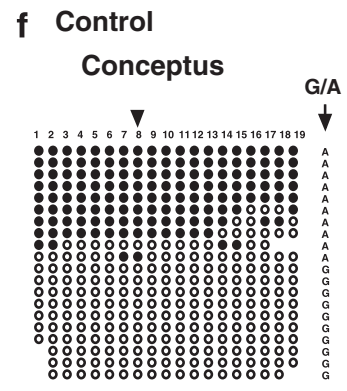

Case 28

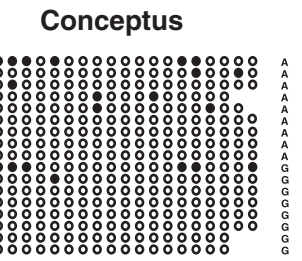

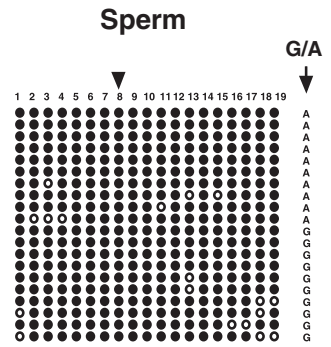

Case 57

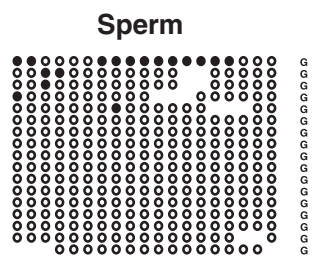

Conceptus

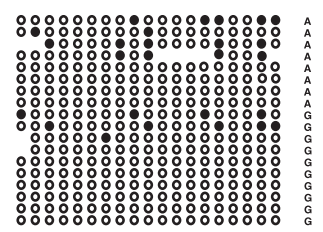

Sperm

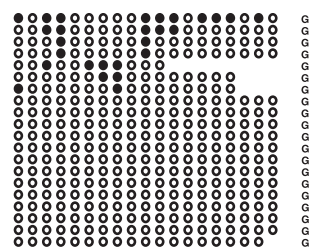

Figure 2 DNA methylation analyses in sperm and ART-treated conceptuses revealed abnormal methylation at H19 and GTL2 DMRs. Genomic structure of the human DMRs of $H 19$ (a). The extent of the region analyzed in this study and GenBank accession number are shown under the line. The horizontal arrows represent primer positions. Vertical arrowhead indicates the unique bisulfite PCR restriction enzyme site analyzed by Taql. Arrow shows the unique C/A polymorphism at nucleotide 8008 in the amplified region of the H19 DMR. The vertical bars represent CpG sites. DNA methylation analyses by COBRA (b) and bisulfite-PCR sequencing (c) of genomic DNA prepared from the sperm and ART conceptus samples fertilized from the same sperm shown to have an abnormal pattern of DNA methylation at the human DMR of $H 19$. Conceptus sample, DNA obtained from ART conceptus; sperm, sperm DNA from the male patient. In the COBRA assay, bisulfite-treated DNA was amplified by PCR and digested with restriction enzymes Taql only cuts the PCR product if the site was originally methylated in the genome. In the bisulfite-PCR sequencing of ART conceptus and sperm DNA at $H 19$ (cases 23, 28, 44, 50, 52 and 67), each row represents a unique methylation profile with an average of 20 clones sequenced for each sample. Closed and open circles represent methylated and unmethylated CpGs, respectively. Samples were heterozygous for a C/A polymorphism allowing differentiation between the two parental alleles. The results are summarized in Table 1. Genomic structure of human DMR of GTL2 (d). Vertical arrowhead indicates the unique bisulfite PCR restriction enzyme site analyzed by Taql and arrow shows the unique G/A polymorphism at nucleotide 51436 in the amplified region of the GTL2 DMR. Like H19, DNA methylation analysis was performed for the human DMR of GTL2 by COBRA (e) and bisulfite-PCR sequencing (f) of genomic DNA (cases 28 and 57) was prepared from the ART conceptus shown to have an abnormal pattern and the matched parental sperm.

Using DNA polymorphisms at the H19 and GTL2 loci, we found seven cases where the precise DNA methylation error was present in the father sperm and the conceptuses (Table 1; Figure 2), suggesting that the methylation errors were preexisting and not a consequence of the ART. We also identified four sperm samples (cases 13, 50, 53 and 70) that showed abnormal DNA methylation that was not present in the conceptus.

\section{Mutation analyses of DNMT3A and DNMT3L}

The consequences of Dnmt $3 a$ and Dnmt $3 L$ deficiency in mice are loss of imprints and oligospermia, so we next 
Table 2 Summary of the DNMT3L and DNMT3A sequence alterations identified in infertile men with abnormal imprint methylation in the sperm

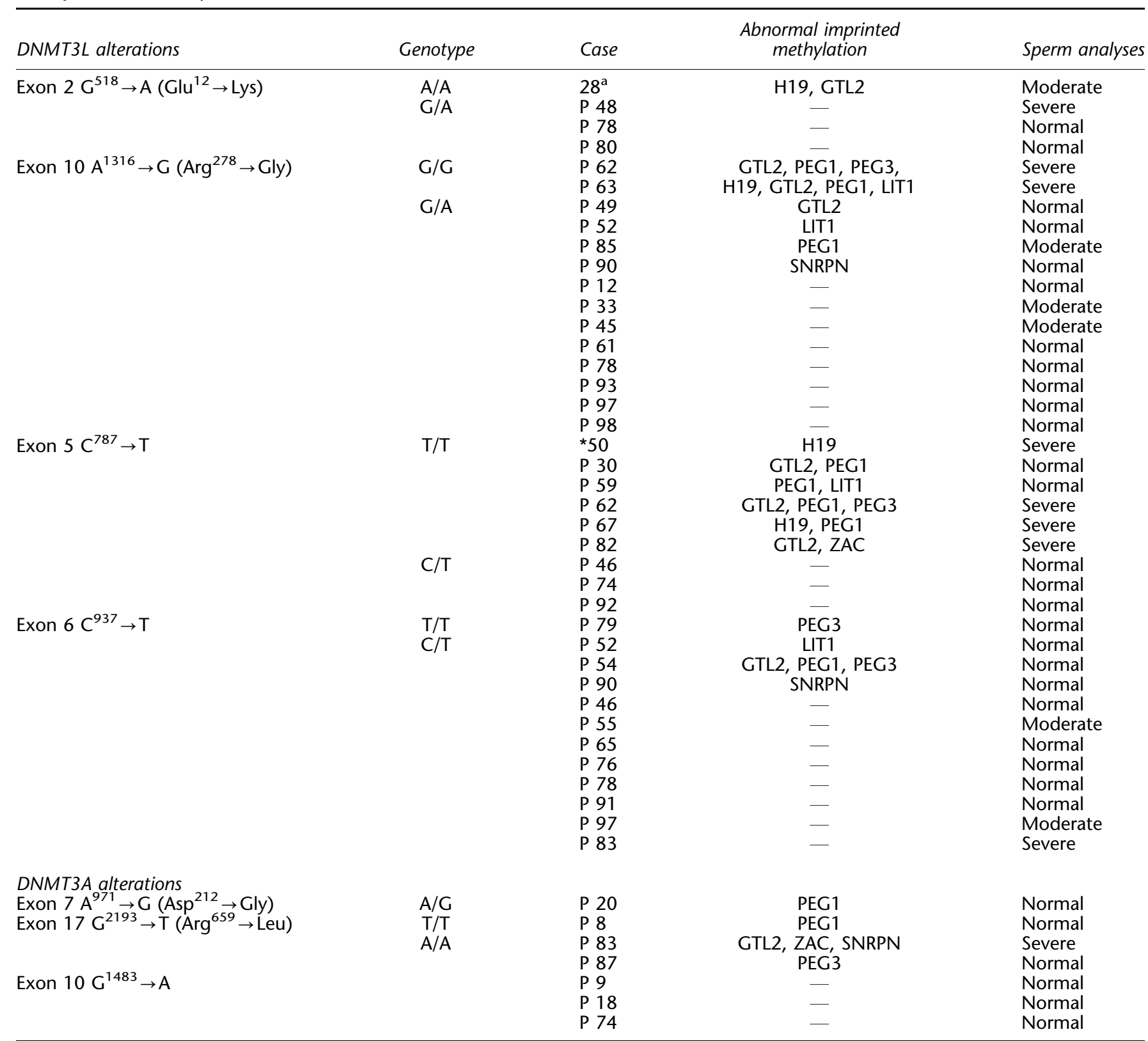

Nucleotide numbering refers to DNMT3L and DNMT3A cDNA sequences AF194032 and AF331856, respectively.

${ }^{a}$ Male patients from this paper with an abnormal imprint in both the conceptus and the sperm. Others samples are previously reported male patients (14).

examined 136 infertile men for gene mutations using SSCP and DNA sequencing. This group included the 7 male patients with an abnormal imprint in both the conceptuses and the sperm, 24 patients for which we previously reported an abnormal sperm imprint ${ }^{19}$ and an additional 105 patients who had undergone some fertility treatment where we had not identified a difference in DNA methylation. Of these, 27 had severe oligospermia, 30 had moderate oligospermia and 79 appeared normal.
We identified two sequence differences in DNMT3L that were predicted to alter the amino-acid sequence, one within exon 2 and one within the methylation enzyme activation motif IV in exon 10 (Table 2). The individual homozygous for the exon 2 polymorphism $\left({ }^{518} \mathrm{G} / \mathrm{G}\right)$ had DNA methylation errors at H19 and GTL2 and moderate oligospermia. Three heterozygous individuals $\left({ }^{518} \mathrm{G} / \mathrm{A}\right)$ showed normal methylation although one had severe oligospermia. Two individuals homozygous for the exon 
10 alteration $\left({ }^{1316} \mathrm{G} / \mathrm{G}\right)$ had aberrant methylation of paternal and maternal imprinted loci and severe oligospermia. Of the twelve individuals that were heterozygous for this polymorphism $\left({ }^{1316} \mathrm{G} / \mathrm{A}\right)$, four showed abnormal methylation whereas eight appeared normal. They all had normal sperm or only moderate oligospermia.

We also identified sequence differences that were predicted to result in nonsense mutations. One was a ${ }^{787} \mathrm{C}$ to $\mathrm{T}$ conversion in exon 5 located in the PHD domain. Six individuals homozygous for this alteration had abnormal methylation at some paternal and maternal loci and four also had severe oligospermia. The three heterozygous individuals had normal-appearing sperm and no detectable methylation errors. One individual homozygous for a nonsense variant $\left({ }^{937} \mathrm{C}-\mathrm{T}\right)$ in exon 6 , also located in a PHD domain, had abnormal methylation at PEG3 in his sperm and three of the eleven individuals heterozygous for this sequence alteration had abnormally methylated sperm but none had oligospermia.

Of the seven male patients with an abnormal imprint in both the ART conceptuses and the sperm, two cases had variations in DNMT3L (case $50,{ }^{787} \mathrm{C} / \mathrm{C}$ in exon 5 and case $28,{ }^{518} \mathrm{G} / \mathrm{G}$ in exon 2 ), which could suggest that these variants affect the function of $D N M T 3 L$.

We identified three types of DNMT3A sequence alterations but these did not correlate with either an abnormal imprint or abnormalities in the number of sperm (Table 2).

In conclusion, we report seven cases where imprinting mutations in ART conceptuses match those present in the parental sperm and in two of these cases, the father also carried an alteration in the sequence of the DNMT3L gene. These findings suggest that the increased prevalence of imprinting disorders linked to ART does not originate solely through the process of ART but, in a significant number of cases, these alterations in DNA methylation preexist in the father's germ line. We may be selecting these cases because they are also linked with a low sperm count.

\section{Discussion}

Although it is clear that the in vitro culture of gametes can result in the altered regulation of imprinted genes, in this study we have identified another source of imprinting errors in ART, direct inheritance from the father's sperm. We found 17 of 78 ART samples (21.8\%) that showed abnormal DNA methylation at one or more than one imprinted loci. Although some of the imprinting errors we identified may have occurred during the process of ART, we identified seven cases where the same imprinting errors were present in the parental sperm and the matched ART sample, suggesting that abnormal hypomethylation at H19 and GTL2 was transmitted directly from the father's sperm. Loss of a paternal methylation imprint cannot account for an increased prevalence of BWS or AS in ART children as these arise from loss of the maternal imprint but could account for the increased frequency of syndromes such as SRS. $^{23-25}$ Given the known role of imprinted genes in regulating embryonic and extraembryonic growth (MRC Mammalian Genetics Unit, Harwell UK, URL: http://www. mgu.har.mrc.ac.uk/research/imprinting/function.html), the increased frequency of low birth weight in ART infants may also be due to alterations at imprinted loci although such changes have not, as yet, been reported. ${ }^{26}$ Other obstetric complications are frequently linked to ART such as miscarriage, placental dysfunction, premature labor, placenta previa and maternal hypertension. ${ }^{27-31}$ These may also reflect accumulated small changes in DNA methylation at imprinted loci.

We identified some samples that showed both paternal and maternal methylation errors. This could suggest a more wide-ranging defect in recognizing or maintaining appropriate methylation in the early conceptus. In this respect, our observation that there are alterations in the DNMT3L gene linked to infertility and alteration in DNA methylation is intriguing. The existence of heterozygous cases and the fact that we only observe the partial loss of imprints could suggest haploinsufficiency or a dominantnegative function either in the developing sperm and/or in the early embryo. Alternatively, the sequence alterations in DNMT3L result in an altered specificity rather than loss of function, which could account for the hypomethylation of two paternal DMRs and gain of a maternal DMR methylation that we observed in sperm DNA of patient 28. In addition, two ART fetuses (cases 23 and 57) showed hypomethylation of both a paternal and a maternal DMR, which might also suggest a problem with the identification of the target sequence. It will clearly be important to test this hypothesis by asking whether the sequence alterations we have identified result in aberrant function in vitro.

\section{Imprint-specific methylation errors and their plasticity}

In all cases, the global methylation status of our samples was not detectably altered suggesting that the DNA methylation marks at imprinted loci are more readily altered. There also appeared to be differences in the vulnerability of different DMRs to alteration. It has been shown that the short tandem repeat elements within the DMRs of some imprinted genes are important for imprinting. ${ }^{32}$ The degree to which imprinted genes are repeat-like may be a factor in determining their methylation status and we are extending our current work to other DNA methylated loci to further investigate this possibility.

In a few cases, the methylation abnormalities in the sperm were not present in the ART conceptus suggesting that either the parental sperm is mosaic for the methylation errors or that remodeling of DNA methylation can 
occur after fertilization. Nutrients, including methyl substrates such as vitamin B6 and folic acid, influence DNA methylation and histone modification at gene promoters and this approach has already been applied to treat autism. ${ }^{33}$ Imprinting errors in sperm at the paternally methylated DMRs may be reversed using a similar approach.

\section{Standard ART treatment}

As a result of our studies and the work of others in this area, we recommend that imprint methylation analyses be added to the routine sperm examination to identify preexisting imprint mutations. The relative ease of COBRA would make this approach feasible within a clinical setting and substantially reduce the likelihood of abnormal samples being used in ART. Altered expression and methylation of imprinted genes is a frequent event in cancer $^{34}$ and it will be important to also determine the frequency of cancer occurrence in ART offspring. A retrospective examination of imprinted loci and the constitution of children born after each ART method will reveal the safest and most ethical approach to use, which will be invaluable for the future development of standard ART treatments.

\section{Acknowledgements}

We thank Miss M Nasu for technical assistance and all the members of our laboratory for their support and valuable suggestions. Patients' agreement was obtained and all work was performed with the approval of the institutional ethics committee and Japan Society of Obstetrics and Gynecology.

This work was supported by grants from the Ministry of Health and Welfare of Japan (19390423 and 20017003), Japan Science and Technology Agency (JST), Avon Support Foundation, Suzuken Memorial Foundation, Takeda Science Foundation, Children's Cancer Association of Japan, Uehara Memorial Foundation, Kampo Medical Foundation, Osteoporosis Foundation, Hiromi Foundation, Daiwa Foundation, NIG Cooperative Research Program (2008-B), Smoking Research Foundation, Nakatomi Foundation, The Salt Science Research Foundation (0829), Nestle Nutrition Council Japan, Kobayashi Institute for Innovative Cancer Chemotherapy, Yamada Bee Farm Grant for Honeybee Research (TA) and Sagawa Cancer Foundation, Suzuken Memorial Foundation (YN). The sponsors of the study had no role in study design, data collection, data analysis, data interpretation or writing the report.

\section{Conflict of interest statement}

None declared.

\section{References}

1 Gosden R, Trasler J, Lucifero D, Faddy M: Rare congenital disorders, imprinted genes, and assisted reproductive technology. Lancet 2003; 361: 1975-1977.

2 Maher ER: Imprinting and assisted reproductive technology. Hum Mol Genet 2005; 14: 133-138.

3 DeBaun MR, Niemitz EL, Feinberg AP: Association of in vitro fertilization with Beckwith-Wiedemann syndrome and epigenetic alterations of KCNQ1OT1 and H19. Am J Hum Genet 2003; 72: 156-160.

4 Surani MA: Imprinting and the initiation of gene silencing in the germ line. Cell 1998; 93: 309-312.

5 Lucifero D, Mertineit C, Clarke HJ, Bestor TH, Trasler JM: Methylation dynamics of imprinted genes in mouse germ cells. Genomics 2002; 79: 530-538.

6 Obata Y, Kono T: Maternal primary imprinting is established at a specific time for each gene throughout oocyte growth. J Biol Chem 2002; 277: 5285-5289.

7 Bowdin S, Allen C, Kirby G et al: A survey of assisted reproductive technology births and imprinting disorders. Hum Reprod 2007; 12: $3237-3240$

8 Doornbos ME, Maas SM, McDonnell J, Vermeiden JP, Hennekam RC: Infertility, assisted reproduction technologies and imprinting disturbances: a Dutch study. Hum Reprod 2007; 9: $2476-2480$.

9 Lucifero D, Chaillet JR, Trasler JM: Potential significance of genomic imprinting defects for reproduction and assisted reproductive technology. Hum Reprod Update 2004; 10: 3-18.

10 Bourc'his D, Xu GL, Lin CS, Bollman B, Bestor TH: Dnmt3L and the establishment of maternal genomic imprints. Science 2001; 294: 2536-2539.

11 Hata K, Okano M, Lei H, Li E: Dnmt3L cooperates with the Dnmt3 family of de novo DNA methyltransferases to establish maternal imprints in mice. Development 2002; 129: 1983-1993.

12 Kaneda M, Okano M, Hata K et al: Essential role for de novo DNA methyltransferase Dnmt3a in paternal and maternal imprinting. Nature 2004; 429: 900-903.

13 Aapola U, Kawasaki K, Scott HS et al: Isolation and initial characterization of a novel zinc finger gene, DNMT3L, on 21q22.3, related to the cytosine-5-methyltransferase 3 gene family. Genomics 2000; 65: 293-298.

14 Chedin F, Lieber MR, Hsieh CL: The DNA methyltransferase-like protein DNMT3L stimulates de novo methylation by Dnmt3a. Proc Natl Acad Sci USA 2002; 99: 16916-16921.

15 Suetake I, Shinozaki F, Miyagawa J, Takeshima H, Tajima S: DNMT3L stimulates the DNA methylation activity of Dnmt3a and Dnmt3b through a direct interaction. J Biol Chem 2004; 279: $27816-27823$.

16 Jia D, Jurkowska RZ, Zhang X, Jeltsch A, Cheng X: Structure of Dnmt3a bound to Dnmt3L suggests a model for de novo DNA methylation. Nature 2007; 449: 248-251.

17 Ooi SK, Qiu C, Bernstein E et al: DNMT3L connects unmethylated lysine 4 of histone $\mathrm{H} 3$ to de novo methylation of DNA. Nature 2007; 448: 714-717.

18 Marques CJ, Carvalho F, Sousa M, Barros A: Genomic imprinting in disruptive spermatogenesis. Lancet 2004; 363: 1700-1702.

19 Kobayashi H, Sato A, Otsu E et al: Aberrant DNA methylation of imprinted loci in sperm from oligospermic patients. Hum Mol Genet 2007; 16: 2542-2551.

20 Kawakami T, Okamoto K, Ogawa O, Okada Y: XIST unmethylated DNA fragments in male-derived plasma as a tumour marker for testicular cancer. Lancet 2004; 363: 40-42.

21 Sinclair AH, Berta P, Palmer MS et al: A gene from the human sex-determining region encodes a protein with homology to a conserved DNA-binding motif. Nature 1990; 346: $240-244$.

22 Suzuki Y, Orita M, Shiraishi M, Hayashi K, Sekita T: Detection of ras gene mutations in human lung cancers by single-strand conformation polymorphism analysis of polymerase chain reaction products. Oncogene 1990; 5: 1037-1043.

23 Bliek J, Terhal P, van den Bogaard MJ et al: Hypomethylation of the $H 19$ gene causes not only Silver-Russell syndrome (SRS) but also isolated asymmetry or an SRS-like phenotype. Am J Hum Genet 2006; 78: 604-614.

24 Källén B, Finnström O, Nygren KG, Olausson PO: In vitro fertilization (IVF) in Sweden: risk for congenital malformations after different IVF methods. Birth Defects Res A Clin Mol Teratol 2005; 73: 162-169. 
25 Svensson J, Björnståhl A, Ivarsson SA: Increased risk of SilverRussell syndrome after in vitro fertilization? Acta Paediatr 2005; 94: $1163-1165$

26 Kanber D, Buiting K, Zeschnigk M, Ludwig M, Horsthemke B: Low frequency of imprinting defects in ICSI children born small for gestational age. Eur J Hum Genet 2009; 17: 22-29.

27 Farr SL, Schieve LA, Jamieson DJ: Pregnancy loss among pregnancies conceived through assisted reproductive technology, United States, 1999-2002. Am J Epidemiol 2007; 12: 1380-1388.

28 Merlob P, Sapir O, Sulkes J, Fisch B: The prevalence of major congenital malformations during two periods of time, 19861994 and 1995-2002 in newborns conceived by assisted reproduction technology. Eur J Med Genet 2005; 1: 5-11.

29 Wang YA, Sullivan EA, Black D, Dean J, Bryant J, Chapman M: Preterm birth and low birth weight after assisted reproductive technology-related pregnancy in Australia between 1996 and 2000. Fertil Steril 2005; 6: 1650-1658.

30 Erez O, Vardi IS, Hallak M, Hershkovitz R, Dukler D, Mazor M: Preeclampsia in twin gestations: association with IVF treatments, parity and maternal age. Arch Gynecol Obstet 2008; 4: 311-317.
31 Romundstad LB, Romundstad PR, Sunde A, von Düring V, Skjaerven R, Vatten LJ: Increased risk of placenta previa in pregnancies following IVF/ICSI; a comparison of ART and non-ART pregnancies in the same mother. Hum Reprod 2006; 9: $2353-2358$

32 Reinhart B, Eljanne M, Chaillet JR: Shared role for differentially methylated domains of imprinted genes. Mol Cell Biol 2002; 22: 2089-2098.

33 Chen WG, Chang Q, Lin Y et al: Derepression of BDNF transcription involves calcium-dependent phosphorylation of MeCP2. Science 2003; 302: 885-889.

34 Feinberg AP, Ohlsson R, Henikoff S: The epigenetic progenitor origin of human cancer. Nat Rev Genet 2006; 1: 21-33.

This work is licensed under the Creative Commons Attribution-NonCommercialShare Alike 3.0 Licence. To view a copy of this licence, visit http://creativecommons.org/licenses/ by-nc-sa/3.0/

Supplementary Information accompanies the paper on European Journal of Human Genetics website (http://www.nature.com/ejhg) 